\title{
Wall Climbing Glass Cleaner Robot
}

\author{
Manish Donode ${ }^{1}$, Shubham Bramhankar ${ }^{2}$, Mohammad Meraj Ansari ${ }^{3}$, Sabbir Ahmad ${ }^{4}$, \\ Bharat Chede $^{5}$, Swapnil Choudhary ${ }^{6}$
}

${ }^{1,2,3,4}$ U.G. Student, ${ }^{5,6}$ Asst Professor Wainganga College of Engineering and Management, Maharashtra, India

\begin{abstract}
The main motive of glass climbing robot is to climb and move on glass surface. To achieve this purpose efficient attachment and detachment is an important aspect. Centrifugal impeller is used which generation the low-pressure area for proper adhesion on the wall surface. This type of robot can take place of humans to carry out hazardous work such as cleaning of glass.
\end{abstract}

\section{I- INTRODUCTION}

$\mathbf{T}$ he purpose of this paper a capable of a simple and light weight robotic structure. It combines a set of motions composed of parallel linear motion, rotational motion and interference avoidance motion. In modern society, there is an increasing need for climbing robots to clean, weld or inspect different kinds of surfaces of high buildings, large oil tanks and rough concrete facilities, replacing workers in these hazardous environments. Consequently, robotic technologies have been developed and applied according to the need sin different fields. However, some problems, such as difficulty in overcoming barriers and complex structures, also emerge. So, the robotic structure develop din this paper will be designed to clean wall glass.

\section{II- PROBLEM STATEMENT}

Currently, market demands many automatic glass leaning systems. The requirements of glass cleaning robot are listed below:
- The size of the robot should be small and light weight form ability and portability

- The robot must be able to clean corner because fouling is left there often

- The robot must be able to sweep the wall pane continuously to prevent stripe pattern on the glass.

- The robot can operate automatically during moving on the glass wall.

\section{III - OBJECTIVE}

The objective of this project is to design a robotic device for used in cleaning glass in high-rise building.

- To Fabricate the Low weight plastic chassis.

- Working of Proximity sensor with microcontroller.

- Analyzing the behavior and characteristic of the proximity sensor

- The prototype of glass cleaning robot that we are developing. The dimensions of prototyped robot are approximately $300 \mathrm{~mm}$ $\mathrm{x} 300 \mathrm{~mm} \times 100 \mathrm{~mm}$ and its weight is approximately $1-1.5 \mathrm{~kg}$.

- The prototyped robot consists of two in dependently driven wheels and an active suction cup. 


\section{International Journal of Innovations in Engineering and Science, www.ijies.net}

\section{IV- LITERATURE REVIEW}

In this chapter following research paper has been studied for the conduction of this project.

Many researchers have worked on wall climbing robot mechanisms and specialized applications.

- To moakiyano, etal has developed as emiselfcontained wall climbing robot with scanning type suction cups which has two vacuum pumps that gave positive results.

- James Jkerley has conferred in his paper about invention of robotic devices, especially to mobile robot that is able to move in caterpillar fashion along a variety of different surfaces.

- Ritesh G. Mahajan and Prof. S. M. Patil explained, the Wall Climbing Robot (WCR) having capability that it can stick on a vertical as well as inclined surface and can easily move over the surface. The targeted capability to stick with surface can be achieved by suction cups. Suction cups create a vacuum pressure used to stick with vertical or inclined surface. For movement(climbing)of robot it is necessary that's one of suction cup should release $\&$ that arrangement is obtained by developing the structure such that in which one frame is used to hold the robot to wall \& other for climbing (vertical movement of robot). The motion of the other frame is carried out by providing rack \& pinion type mechanism. The whole action is controlled by an Arduino and the commands sending on the Zig-bee through the mobile.

\section{V- METHODOLOGY}

Glass Cleaning Robot There is already a glass cleaning robot that is design. The robot's weight is less than $5 \mathrm{~kg}$, including the weight of battery and bush. The robot size $300 \mathrm{~mm} \times 300 \mathrm{~mm} \times 100 \mathrm{~mm}$. The robot mechanics mass how in Figure below was designed under focusing on the glass cleaning robot for just a single wall glass. The robot moves on glass by two-wheel locomotion mechanism with holing the body on the surface using a suction cup vacuumed by a pump. The control system which includes traveling direction controller using accelerometer and traveling distance controller using rotary encoder and wheel sensors were installed for autonomous operation. To climb, those robots used various types of adhesion mechanism to grip the wall.



Fig. 1 - Wall Climbing Glass Cleaner Robot

\section{Requirement of Components-}

\section{Suction cup}

Most commonly used in higher building. It can be either a single large suction cup or multiple small suction cups on each of the robot's foot. The suction cup has excellent grip up to $1 \mathrm{~atm}$ and ease of use. The gripping can be controlled simply by closing/opening the valve.

\section{Wheels}

It is used to move forward direction and backward direction also move left and right side.This is rotate with help of DC gear motor.

\section{DC Gear Motor}

The combination of gear and motor that is called DC gear motor. It utilizes Servo system utilizing positive input control. Here accuracy of rigging revolution is greatly required which could be made accessible just by utilizing servo engines. The order is given to it by controller which gives sign for particular turn plot. For giving summons for forward and retrogressive turn, encoders are introduced on the focal body.

\section{Low weight plastic chassis}

Easy to operate robot's lightweight chassis to move. Maximum weight is less than $5 \mathrm{~kg}$.

\section{Suction cup}

It can be either a single large suction cup or multiple small suction cups on each of the robot's foot. The suction cup has excellent grip up tolatm and ease of use. The gripping can be controlled simply by closing/opening the valve

\section{Proximity Sensor}

- We are using Proximity Sensor in our project 


\section{International Journal of Innovations in Engineering and Science, www.ijies.net}

because of the following reasons: -

- Inductive proximity Sensor has highest accuracy among all the other proximity sensors.

- It has non-contact detection of the object.

- It has short response type.

- It has along life due ton on-contact output.

- It can't detect non-metal objects in which current is not flowing.

\section{LIPO battery}

- A LiPo cell has a nominal voltageof3.7V.

- It is not, however, the full charge voltage of the cell.

- LiPo batteries are fully charged when they reach $4.2 \mathrm{v} / \mathrm{cell}$, and their minimum safe charge, as we will discuss in detail later, is3.1v/cell.

- $\quad 3.7 \mathrm{v}$ is pretty much in the middle, and that is the nominal charge of the cell.

\section{Cleaning Mechanism:}

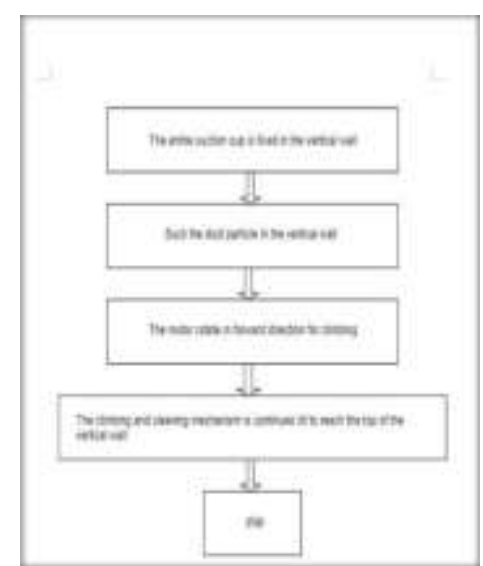

Fig. 2 - Diagram of Cleaning Mechanism

\section{Advantage}

- $\quad$ Easy to handle

- This project does not require any external arrangement.

- It required simple maintenance.

\section{Future application: -}

- Wireless/wired video survey alliance can be possible.

- Consumer applications (window cleaning and painting)

- Inspections (building, aircraft \& bridges, Pipes) etc.
- Wall/glass cleaning and water sprinklers can be mounted.

\section{VI- CONCLUSION}

- $\quad$ The application of "wall climbing glass cleaner robot"

- $\quad$ Time reduces for dust cleaning on higher building.

- $\quad$ To reduce man effort.

- It is used to climb on glass wall safely.

- It is used to avoid man injury.

- This robot moved on glass wall smoothly.

\section{REFERENCES}

[1] Frey,C.B.;Osborne,M.A.Thefutureofemployment:How susceptiblearejobstocomputerisation.Retriev.Sept.201 $3,7,2013$.

[2] InternationalFederationofRobotics.ServiceRobotStatis tics.Available online: http://www.ifr.org/servicerobots/statistics/(accessedo n28 June 2016).

[3] Aldred,J.BurjKhalifa-Anewhighforhigh-performance concrete.Proc.Inst.Civ.Eng.2010,163,66-73.

[4] Baker, W.F. The World's tallest building. Available online:http://www.structuremag.org/wpcontent/uploads/2014/08/D-Spotlight-Burj-June11 1.pdf(accessedon 28 June2016).

[5] Baker,W.F.;Korista,D.S.;Novak,L.C.Burj Dubai: Engineering the world's tallest building. Structure.

[6] Weismantle,P.A.;Smith,G.L.;Sheriff,M.Burj Dubai: Anarchitecturaltechnicaldesigncasestudy.Struct.Des.T all Spec.Build. 2007,16,335-360.

[7] ZELJIC, A.S. Shanghai Tower Façade Design Process. International Conference of Building Envelope Systems. Available online: http://www.gensler.com/uploads/documents/Shanghai_ Tower_Facade_Design_Process_11_10_2011.pdf(acc essedon28 June2016).

[8] Xia,J.;Poon,D.;Mass,D.Casestudy:ShanghaiTower.C TBUHJ.2010,2,12-18.

[9] Zhaoa, X.; Ding, J.; Suna, H. Structural design of shanghai tower for wind loads. Procedia Eng. 2011,14, 1759- 1767.10.BBC. Shanghai Window Cleaning Cradle Swings Out of Control. Available online: http://www.bbc.com/news/world-asia-china32176401(accessedon 28June2016). 